(2)

OPEN ACCESS

\title{
Acute aortic dissection with highly compressed true lumen: unanticipated pitfall of point-of-care ultrasonography
}

\author{
Hisashi Dote (1) , ${ }^{1}$ Masaaki Koide, ${ }^{2}$ Shunsuke Kobayashi, ${ }^{1}$ Takahiro Atsumi ${ }^{1}$
} and Critical Care Medicine, Seirei Hamamatsu Hospital, Hamamatsu, Japan ${ }^{2}$ Department of Cardiovascular Surgery, Seirei Hamamatsu Hospital, Hamamatsu, Japan Dr Hisashi Dote; hisashi.dote@gmail.com

Accepted 16 February 2021
'Department of Emergency

Correspondence to

\begin{abstract}
SUMMARY
A 46-year-old man presented with sudden onset of chest pain. He was in cardiogenic shock at arrival. Based on the results of ECG and echocardiogram, he was diagnosed with ST-segment elevation myocardial infarction. Point-of-care ultrasonography (POCUS) did not reveal acute aortic dissection (AAD). During an emergency coronary angiography, aortic dissection was detected and computed tomographic angiography (CTA) revealed Stanford type A AAD with a highly compressed true lumen. Because of this form of aortic dissection, the enlarged false lumen could be potentially misidentified as a normal aorta in POCUS. Although POCUS is useful when $A A D$ is suspected, we should not overestimate its findings and lower the threshold for CTA.
\end{abstract}

\section{BACKGROUND}

Acute aortic dissection (AAD) is a fatal disease that presents in the emergency department (ED). However, the symptoms and severity of AAD at the time of presentation vary and are often difficult to diagnose. As AAD sometimes mimics myocardial infarction, emergency physicians (EPs) are faced with a difficult decision. Although point-ofcare ultrasonography (POCUS) has proven to help distinguish between these two diseases, ${ }^{1}$ we experienced a case in which the form of the dissection made it difficult to diagnose using POCUS.

\section{CASE PRESENTATION}

A 46-year-old Japanese man suddenly developed severe chest pain. He had no significant medical or family history, and smoked one pack of cigarettes per day. The symptoms appeared while he was working in a restaurant. He arrived at the ED 30 min after onset.

The initial vital signs of the subject were as follows: blood pressure, $183 / 120 \mathrm{~mm} \mathrm{Hg}$; heart

Check for updates

(c) BMJ Publishing Group Limited 2021. Re-use permitted under CC BY-NC. No commercial re-use. See rights and permissions. Published by BMJ.

To cite: Dote $\mathrm{H}$, Koide $\mathrm{M}$, Kobayashi S, et al. BMJ Case Rep 2021;14:e239328. doi:10.1136/bcr-2020239328



Figure 1 Initial ECG showing ischaemic changes (ST elevation in the II, III, aVF, V1 and V2 leads).

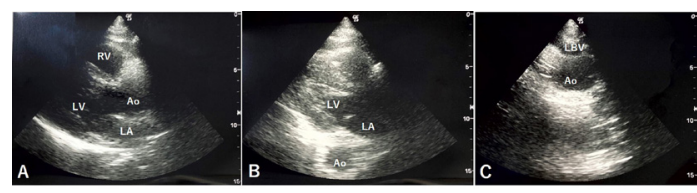

Figure 2 Point-of-care ultrasonogram. (A) Left parasternal long-axis view of the heart. (B) The descending aorta is posterior to the left ventricle. (C) The suprasternal view. Aortic dissection cannot be identified on any image. Ao, aorta; LA, left atrium; LBV, left brachiocephalic vein; LV, left ventricle.

rate, 98 beats/min; respiratory rate, 26 breaths/ min; oxygen saturation, $99 \%$ on $10 \mathrm{~L}$ of oxygen per minute. He was in a state of restlessness and had large amounts of cold sweat. On auscultation, no abnormal heart or breathing sounds were observed. Further, there was no difference in blood pressure or radial arterial palpitation in either of the upper extremities.

\section{INVESTIGATIONS}

The laboratory data showed a normal troponin I level of under $10 \mathrm{pg} / \mathrm{mL}$ (normal range: under $26.2 \mathrm{pg} / \mathrm{mL}$ ) and elevated lactate level $32 \mathrm{mg} / \mathrm{dL}$ (normal range: $4.5-18.0 \mathrm{mg} / \mathrm{dL}$ ). ECG showed ST elevation in the II, III, aVF, V1, V2 and V4R leads (figure 1). Thoracic echocardiography showed decreased contraction of the inferior left ventricular wall. Chest radiography revealed mediastinal widening $(97 \mathrm{~mm})$. Aortic dissection-oriented POCUS with left parasternal, apical, suprasternal, subcostal and abdominal views did not reveal an intimal flap, a thoracic aorta dilation, a massive pericardial effusion or an aortic valve regurgitation

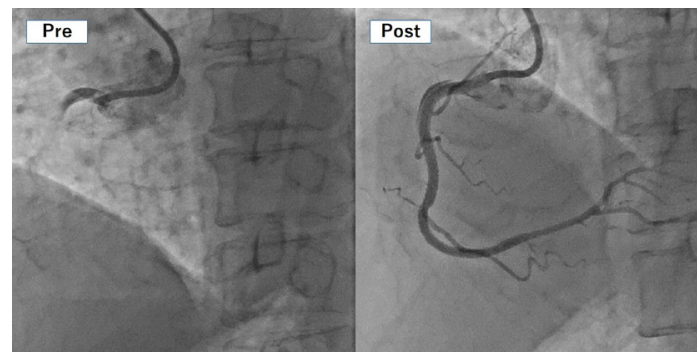

Figure 3 Coronary angiography shows the complete occlusion of right coronary artery (pre). After percutaneous coronary intervention, TIMI-3 flow was obtained (post). TIMI, thrombolysis in myocardial infarction. 


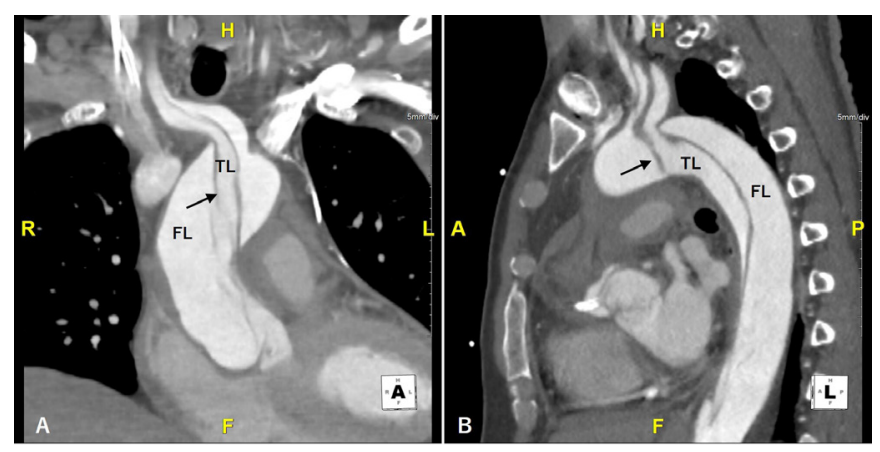

Figure 4 Computed tomographic angiography showing aortic dissection in the aortic arch in coronal view (A) and sagittal view (B). Intimal flap is indicated by black arrow. $\mathrm{FL}$, false lumen; $\mathrm{TL}$, true lumen.

(AR; figure 2). The D-dimer levels were not determined during the ED stay.

\section{DIFFERENTIAL DIAGNOSIS}

He was diagnosed with ST-segment elevation myocardial infarction (STEMI). After the administration of aspirin and prasugrel, an emergency coronary angiography (CAG) was performed. During CAG, a dissection was detected in the ascending aorta. The right coronary artery was obstructed and drug-eluting coronary stents were placed (figure 3). After CAG and percutaneous coronary intervention, computed tomographic angiography (CTA) was performed. It revealed a Stanford type A AAD with a highly compressed true lumen (figures 4 and 5), large intestinal ischemia and left renal infarction. The DeBakey type I aortic dissection extended to the bilateral internal iliac arteries (figure 6).

\section{TREATMENT}

He underwent emergency thoracic aortic graft replacement and open stent grafting.

\section{OUTCOME AND FOLLOW-UP}

After an extensive bowel resection, he was discharged from the intensive care unit.

\section{DISCUSSION}

$\mathrm{AAD}$ is a lethal condition in the ED. The International Registry of Acute Aortic Dissection reported that the overall mortality
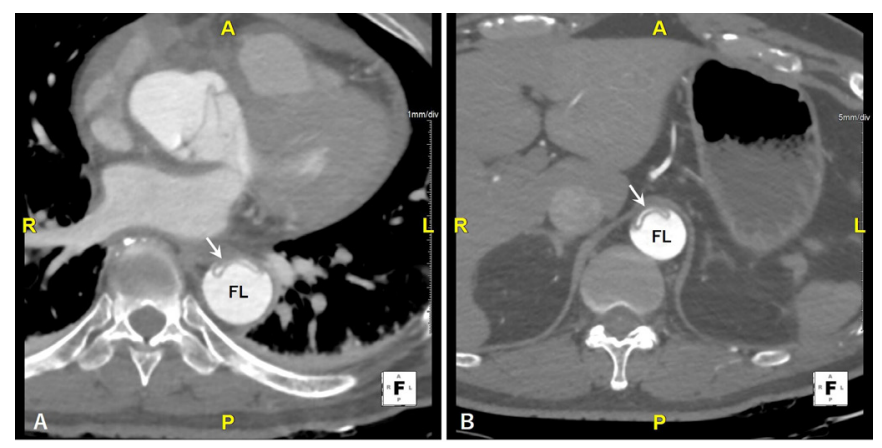

Figure 5 Computed tomographic angiography showing aortic dissection at the descending aorta with a highly compressed true lumen (white arrow) and false lumen (FL) resembling a normal aorta. Findings have been detected at the same level as the left parasternal long-axis view $(A)$ and subcostal view (B) by point-of-care ultrasonography.

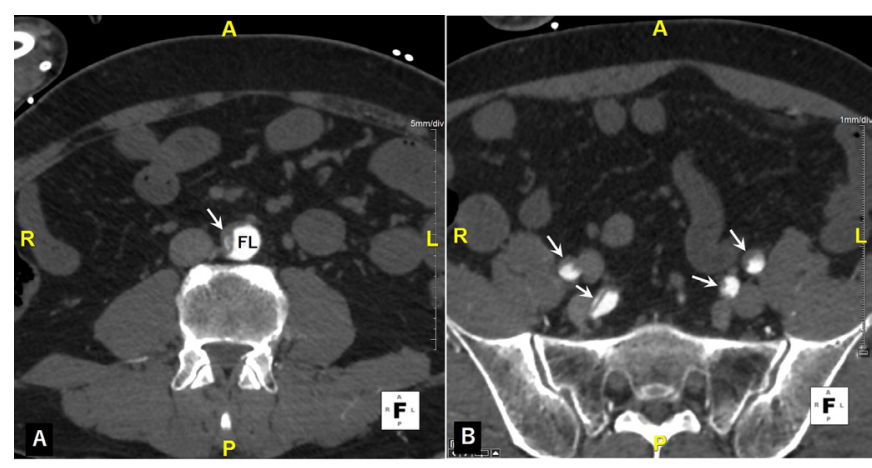

Figure 6 Computed tomographic angiography showing aortic dissection at the abdominal aorta below the renal artery branch points (A), and the external and internal iliac arteries (B). White arrows show highly compressed true lumen. $\mathrm{FL}$, false lumen.

rate of Stanford type A AAD is aproximately $22 \% .{ }^{1}$ This large multicenter detabase also revealed that the $25 \%$ of $\mathrm{AAD}$ are initially diagnosed by thoracic echocardiography. ${ }^{1}$

Occasionally, the dissection of the ascending aorta occludes the coronary artery and mimics an STEMI. Discriminating between an AAD and a primary STEMI is very important for decisions regarding treatment plans. Aortic dissection-oriented POCUS has been reported as a useful tool to help discriminate these conditions. ${ }^{2}$ Another report suggests that the dissection of the aortic arch could be diagnosed using the suprasternal view. ${ }^{3}$ Many parts of the thoracic aorta can be evaluated using POCUS.

Direct POCUS findings suggesting AAD are the presence of an intimal flap, intramural aortic haematoma (circular or crescentic thickening of the aortic wall $>5 \mathrm{~mm}$ ) and penetrating aortic ulcer (crater-like outpouching with jagged edges in the aortic wall). Indirect findings include dilation of the aorta $(>40 \mathrm{~mm})$, pericardial effusion and cardiac tamponade and AR more than moderate levels. ${ }^{4}$ Detection of any POCUS findings suggesting AAD has a sensitivity of $88 \%$ (95\% CI: $76 \%$ to $95 \%)$.

CTA findings revealed that our patient had a highly compressed true lumen and enlarged false lumen. Because of this form of aortic dissection, there was potential to misidentify the enlarged false lumen as a normal aorta on POCUS. Although the dissection of the aortic arch was relatively clear of the true lumen from CTA, given that evaluation of the aortic arch from the suprasternal notch view using ultrasonography is not so easy for EPs, ${ }^{6}$ we could not visualise adequate findings.

Guidelines for the diagnosis and management of patients with thoracic aortic disease recommend estimating pretest risk during initial management. ${ }^{7}$ Our patient presented with an Aortic Dissection Detection Risk Score $>1$ and should have been rated as high risk. ${ }^{7}$ Mediastinal widening on chest radiography was also observed. A mediastinal width $>87 \mathrm{~mm}$ demonstrated high sensitivity in the diagnosis of a probable Stanford type A AAD. ${ }^{8}$ If we had focused on these findings and had performed CTA before CAG, the treatment plan would have changed to emergency surgery. If AAD is suggested in an ED, POCUS is useful; however, detecting aortic dissection is occasionally difficult depending on the form. In our case, the true lumen from the abdominal aorta to the iliac artery was also highly compressed, thus we think that diagnosis by POCUS was difficult if we tested these area. Furthermore, the diagnostic accuracy of POCUS depends in no small part on the skill of the operator. Therefore, we should not overestimate the POCUS findings and lower the threshold for CTA. 
Learning points

- Point-of-care ultrasonography (POCUS) is a useful tool to discriminate acute aortic dissection (AAD) and other mimics.

- One of the pitfalls of POCUS is that AAD with a highly compressed true lumen and enlarged false lumen could be difficult to identify.

- We should not overestimate the POCUS findings and lower the threshold for computed tomographic angiography.

Contributors HD drafted the article, and all authors contributed substantially to its revision. TA supervised the conduct of the reports.

Funding The authors have not declared a specific grant for this research from any funding agency in the public, commercial or not-for-profit sectors.

Competing interests None declared.

Patient consent for publication Obtained.

Provenance and peer review Not commissioned; externally peer reviewed.

Open access This is an open access article distributed in accordance with the Creative Commons Attribution Non Commercial (CC BY-NC 4.0) license, which permits others to distribute, remix, adapt, build upon this work non-commercially, and license their derivative works on different terms, provided the original work is properly cited and the use is non-commercial. See: http://creativecommons.org/ licenses/by-nc/4.0/.

\section{ORCID iD}

Hisashi Dote http://orcid.org/0000-0002-9323-656X

\section{REFERENCES}

1 Evangelista A, Isselbacher EM, Bossone E, et al. Insights from the International registry of acute aortic dissection: a 20-year experience of collaborative clinical research. Circulation 2018;137:1846-60.

2 Chenkin J. Diagnosis of aortic dissection presenting as ST-elevation myocardial infarction using point-of-care ultrasound. J Emerg Med 2017;53:880-4.

3 Fernando SM, Kisilewicz M, Millington SJ. View from the top: point-of-care ultrasound diagnosis of type A aortic dissection using the suprasternal view. J Emerg Med 2018;54:e13-14.

4 Morello F, Santoro M, Fargion AT, et al. Diagnosis and management of acute aortic syndromes in the emergency department. Intern Emerg Med 2021;16:171-81.

5 Nazerian P, Vanni S, Castelli M, et al. Diagnostic performance of emergency transthoracic focus cardiac ultrasound in suspected acute type A aortic dissection. Intern Emerg Med 2014:9:665-70.

6 Kinnaman KA, Kimberly HH, Pivetta E, et al. Evaluation of the aortic arch from the suprasternal Notch view using focused cardiac ultrasound. J Emerg Med 2016:50:643-50.

7 Hiratzka LF, Bakris GL, Beckman JA. 2010 ACCF/AHA/AATS/ACR/ASA/SCA/SCAI/SIR/ STS/SVM guidelines for the diagnosis and management of patients with thoracic aortic disease: Executive summary: a report of the American College of cardiology Foundation/American heart association Task force on practice guidelines, American association for thoracic surgery, American College of radiology, American stroke association. Circulation 2010;121:266-369.

8 Funakoshi H, Mizobe M, Homma Y, et al. The diagnostic accuracy of the mediastinal width on supine anteroposterior chest radiographs with nontraumatic Stanford type A acute aortic dissection. J Gen Fam Med 2018;19:45-9.

Copyright 2021 BMJ Publishing Group. All rights reserved. For permission to reuse any of this content visit

https://www.bmj.com/company/products-services/rights-and-licensing/permissions/

BMJ Case Report Fellows may re-use this article for personal use and teaching without any further permission.

Become a Fellow of BMJ Case Reports today and you can:

- Submit as many cases as you like

- Enjoy fast sympathetic peer review and rapid publication of accepted articles

- Access all the published articles

- Re-use any of the published material for personal use and teaching without further permission

Customer Service

If you have any further queries about your subscription, please contact our customer services team on +44 (0) 2071111105 or via email at support@bmj.com.

Visit casereports.bmj.com for more articles like this and to become a Fellow 